\title{
Pengaruh Durasi Waktu Pada Sexing Spermatozoa Sapi Bali Terhadap Kualitas Dan Efektivitas Sexing Spermatozoa Dengan Menggunakan Alat Electric Separating Sperm (ESS)
}

\author{
(THE EFFECT OF DURATION ON SEXING SPERMATOZOA BALI CATTLE ON \\ QUALITY AND EFFECTIVENESS SEXING SPERMATOZOA USED ELECTRIC \\ SEPARATION SPERM (ESS))
}

\author{
Lukman Ashari $^{1 *}$, Imam Mustofa ${ }^{2}$, Maya Nurwartanti Yunita ${ }^{3}$, Trilas Sardjito ${ }^{2}$, \\ Amung Logam Saputro ${ }^{4}$, Ragil Angga Prastiya ${ }^{2}$ \\ ${ }^{1}$ Bachelor of Veterinary Medicine, \\ ${ }^{2}$ Department of Veterinary Reproduction, \\ ${ }^{3}$ Department of Veterinary Microbiology, \\ ${ }^{4}$ Department of Clinic and Animal Hospital, \\ Faculty of Veterinary Medicine, Universitas Airlangga, \\ UNAIR C-Campus Mulyorejo, Surabaya, Jawa Timur, Indonesia, 60115 \\ Telp. (031)5993016, Fax. (031)5993015 \\ *Corresponding author: lukman.ashari-2014@ fkh.unair.ac.id
}

\begin{abstract}
Abstrak
Tujuan penelitian ini adalah mengetahui perbedaan kualitas (viabilitas, motilitas dan abnormalitas) spermatozoa Sapi jantan Bali hasil sexing menggunakan alat ESS yang dialiri listrik selama lima menit dan sepuluh menit pada sisi anoda dan katoda dan mengetahui perbedaan efektivitas pemisahan spermatozoa Sapi Bali hasil sexing menggunakan alat ESS yang dialiri listrik selama lima menit dan sepuluh menit pada sisi anoda dan katoda. Penelitian ini menggunakan Sapi Bali yang berumur 4 tahun sampai 7 tahun dengan motilitas di atas $45 \%$ dan di bawah $60 \%$. Penelitian ini menggunakan diluter tris kuning telur. Sexing spermatozoa menggunakan alat ESS yang dialiri listrik dengan durasi 5 menit dan 10 menit pada masing-masing anoda dan katoda. Hasil penelitian ini menunjukan kualitas (viabilitas, motilitas dan abnormalitas) mengalami penurunan. Kualitas terbaik pada sexing spermatozoa terdapat pada durasi lima menit. Efektivitas pemisahan spermatozoa yang paling baik yaitu pada durasi sepuluh menit pada sisi katoda spermatozoa X sebesar $62,17 \pm 0,240 \%$ dan pada

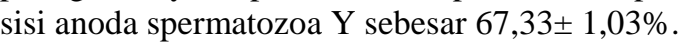

Kata kunci: sexing spermatozoa, Electric Separating Sperm, Sapi Bali, electrophoresis

\begin{abstract}
The aim of this research was to know the differences of quality (viability, motility and abnormality) spermatozoa Bali bulls result of sexing used ESS which powered by electricity for five minutes and ten minutes on anode and cathode side and know the differences effectiveness of sexing spermatozoa Bali bulls which powered by electricity for five minutes and ten minutes on the side of anode and cathode. This study used Bali bulls aged 4 to 7 years old with motility above $45 \%$ and below $60 \%$. This research used eggs yolk tris dilution. Sexing spermatozoa used ESS which powered by electricity for five minutes and ten minutes on anode and cathode side. The results of this study showed quality (viability, motility, and abnormality) decreased. The best quality of sexing spermatozoa on five minutes duration. The best effectiveness of sexing spermatozoa on the ten minute duration $X$ sperm on cathode side $62,17 \pm 0,240 \%$ and $Y$ sperm on anode side 67,33 $\pm 1,03 \%$.
\end{abstract}

Key words: sexing spermatozoa, Electric Separating Sperm, Bali cattle, electrophoresis

\section{PENDAHULUAN}

Sapi Bali merupakan plasma nutfah sapi lokal Indonesia yang sudah tersebar hampir seluruh provinsi di Indonesia dan mempunyai perkembangan cukup pesat karena mempunyai keunggulan yaitu mempunyai daya adaptasi yang baik terhadap lingkungan buruk dan mempunyai fertilitas yang baik yaitu $83 \%$ sehingga dapat digunakan untuk usaha sapi potong (Guntoro, 
2002). Sapi potong di Indonesia agar dapat mengimbangi permintaan dalam negeri sehingga perlu dilestarikan kemurniannya dan dikembangkan produktivitasnya dengan menggunakan penerapan bioteknologi reproduksi. Penerapan bioteknologi reproduksi pada sapi yang digunakan adalah teknolgi sexing spermatozoa (Rodiah dkk., 2015).

Teknologi sexing spermatozoa telah berhasil memisahkan spermatozoa berkromosom $\mathrm{X}$ pada sapi perah yang digunakan untuk memperoleh sapi pedet betina (Taylor, 2005). Pemisahan spermatozoa berkromosom Y digunakan pada sapi potong untuk memperoleh sapi pedet jantan (Said dkk., 2005). Salah satu alat teknologi sexing yaitu menggunakan alat Electric Separating Sperm (ESS) yang mempunyai kelebihan yaitu lebih murah, cepat, mudah dalam melakukan sexing spermatozoa. ESS bekerja pada tegangan listrik rendah yaitu 1.5 Volt. Alat ini mampu memisahkan kromosom $\mathrm{X}$ dan $\mathrm{Y}$ pada spermatozoa dalam waktu yang relatif singkat pada domba Merino (Saputro, 2012).

Upaya memodifikasi sexing spermatozoa terus dilakukan untuk mendapatkan kualitas dan kuantitas spermatozoa yang memenuhi syarat untuk digunakan pada program IB. Durasi waktu sexing yang tepat diprediksi akan dapat memberikan hasil sexing yang optimal (Sunarti dkk., 2016).

Tujuan penelitian ini adalah mengetahui perbedaan kualitas (viabilitas, motilitas dan abnormalitas) spermatozoa Sapi jantan Bali hasil sexing menggunakan alat ESS yang dialiri listrik selama lima menit dan sepuluh menit pada sisi anoda dan katoda dan mengetahui perbedaan efektivitas pemisahan spermatozoa Sapi Bali hasil sexing menggunakan alat ESS yang dialiri listrik selama lima menit dan sepuluh menit pada sisi anoda dan katoda.

\section{METODE PENELITIAN}

Penelitian ini dilaksanakan di Balai Besar Inseminasi Buatan Singosari Malang dan pemeriksaan morfometri di Laboratorium Patologi UNAIR Surabaya pada bulan Januari dan Februari 2018. Penelitian ini menggunakan tiga ekor sapi Bali di BBIB Singosari yang berumur 4-7 tahun. Penelitian ini menggunakan semen segar Sapi yang berada di BBIB (Balai Besar Inseminasi Buatan) Singosari. Semen yang digunakan adalah semen yang mempunyai motilitas $45 \%$ ke atas.

Semen sapi Bali diambil menggunakan vagina buatan 2 kali dalam seminggu lalu diperiksa kelayakannya, setelah itu sampel spermatozoa siap untuk di separasi menggunakan alat Electric Separating Sperm (ESS). Pemeriksaan semen miliputi pemeriksaan makrokopis dan mikrokopis. Pemeriksaan makrokopis meliputi pemeriksaan volume, warna, $\mathrm{pH}$ dan konsistensi. Pemeriksaan mikroskopis meliputi konsentrasi, motilitas, viabilitas, abnormalitas dan morfometri luas kepala spermatozoa.

Penelitian ini menggunakan rancangan acak lengkap yaitu faktor yang mempengaruhi uji hanya berasal dari satu faktor saja yaitu durasi waktu yang berbeda (Al-Arif, 2016). Penelitian ini menggunakan 6 ulangan dan hasil penilitian di uji menggunakan ANOVA. Berikut masingmasing perlakuan: (P0) Semen sapi diberikan diluter tris kuning telur tanpa disexing; (P1) Semen sapi diberikan diluter tris kuning telur selanjutnya disexing menggunakan alat ESS dengan tegangan 1,5 volt selama 5 menit; (P2) Semen sapi diberikan diluter tris kuning telur selanjutnya disexing menggunakan alat ESS dengan tegangan 1,5 volt selama 10 menit.

Pemeriksaan motilitas massa dilakukan dengan cara melihat dibawah mikroskop cahaya pembesaran 10x10 tanpa ditutup dengan cover glass. Kriteria penilaian motilitas massa dapat dilakukan dengan melihat aktivitas gerakan massa berupa gelombang dimana cepat berpindah mendapat nilai +++ , sedang mendapat nilai ++ dan kurang dengan nilai + (Tambing, dkk., 2003; Pamungkas,dkk., 2008).

Penilaian motilitas individu spermatozoa dilakukan dengan cara menempatkan satu tetes spermatozoa pada object glass yang ditutup dengan cover glass dan diamati dibawah mikroskop pembesaran 400x. Pengamatan dilakukan secara subjektif terhadap spermatozoa yang bergerak progresif dengan angka yang 
diberikan berkisar antara 0 hingga 100\% (Rizal, 2005).

$\%$ motilitas $=\frac{\text { spermatozoa bergerakprogesif }}{\text { spermatozoayang diamati }} \times 100 \%$

Pemeriksaan viabilitas spermatozoa dilakukan dengan menggunakan preparat ulas eosin-negrosin. Cara kerjanya adalah semen diteteskan pada object glass menggunakan ose. Kemudian eosin-negrosin diteteskan menggunakan ose lain dan dicampurkan dengan semen yang sudah diteteskan di atas object glass sebelumnya. Campuran semen dengan eosinnegrosin dibuat olesan dengan ujung object glass yang lain hingga terbentuk olesan sepanjang permukaan object glass. Kemudian preparat ulas dikeringkan dan diamati dibawah mikroskop dengan pembesaran 400x. Spermatozoa yang masih hidup tidak menyerap warna sedangkan spermatozoa yang sudah mati menyerap warna dan berwarna merah. Persentase spermatozoa hidup dapat dihitung menggunakan rumus persentase spermatozoa hidup sama dengan jumlah spermatoza hidup dibagi spermatozoa yang diamati dikali 100 persen (Ducha, dkk., 2013 ; Varasofiari, dkk., 2013).

$\%$ viabilitas $=\frac{\text { spermatozoa hidup }}{\text { spermatozoa yang diamati }} \times 100 \%$

Pemeriksaan abnormalitas spermatozoa adalah hasil ulasan eosin-negrosin untuk pemeriksaan viabilitas, kemudian dilanjutkan pengamatan dibawah mikroskop cahaya pembesaran 400x (Susilawati, 2016).Persentase abnormalitas spermatozoa dapat dihitung menggunakan rumus abnormalitas spermatozoa sama dengan spermatozoa abnormal dibagi spermatozoa yang diamati dikali 100 persen (Ridwan, 2009).

$\%$ abnormalitas $=\frac{\text { spermatozoa abnormalitas }}{\text { spermatozo yang diamati }} \times 100 \%$

Pemeriksaan morfometri menggunakan mikroskop NISS Element dengan pembesaran 1000x. cara pilih ikon area dan block area kepala spermatozoa sehingga menhasilkan luas kepala. Luas kepala spermatozoa yang lebih besar dari rata-rata luas kepala spermatozoa adalah spermatozoa berkromosom $\mathrm{X}$ dan luas kepala spermatozoa lebih kecil dari rata-rata spermatozoa adalah spermatozoa berkromosom Y (Garner and Hafez, 2008).

$\%$ spermatozoa $\mathrm{X}=\frac{\text { JumlahspermatozoaX }}{100} \times 100 \%$

$\%$ spermatozoa $\mathrm{Y}=\frac{\text { JumlahspermatozoaY }}{100} \times 100 \%$

\section{HASIL DAN PEMBAHASAN}

Volume pada semen segar Sapi Bali yang digunakan dalam penelitian ini termasuk mendekati normal karena volume semen segar sapi yang nomal yaitu 5-8 ml (Toelihere, 1985). Volume semen segar Sapi Bali dalam penelitian ini adalah 4,95 $\pm 1,36 \mathrm{ml}$ (Tabel 1). Pemeriksaan makrokopis semen segar menunjukan $\mathrm{pH}$ $6,6 \pm 0,27$ dengan warna putih kekuningan. Ratarata semen segar sapi normal memiliki $\mathrm{pH}$ 6,47,8 dengan warna putih kekuningan (Garner and Hafez, 2008).

Tabel 1. Hasil pemeriksaan semen segar Sapi Bali

\begin{tabular}{cc}
\hline Parameter & Nilai \pm SD \\
\hline Volume $(\mathrm{ml})$ & $4,95 \pm 1,36$ \\
Warna & Putih kekuningan \\
pH & $6,6 \pm 0,27$ \\
Motilitas $(\%)$ & $48,33 \pm 2,58 / 2-3$ \\
Konsentrasi $\left(10^{6} / \mathrm{ml}\right)$ & $1001,33 \pm 148,59$ \\
\hline
\end{tabular}

Tabel 2. Motilitas, viabilitas, abnormalitas spermatozoa pada sisi katoda dan anoda setelah sexing

\begin{tabular}{cccccc}
\hline \multirow{2}{*}{ Parameter } & \multirow{2}{*}{ Kontrol } & \multicolumn{2}{c}{ 5 menit } & \multicolumn{2}{c}{ 10 menit } \\
\cline { 3 - 6 } & & Katoda & Anoda & Katoda & Anoda \\
\hline Motilitas(\%) & $46,67^{\mathrm{a}} \pm 2,58$ & $44,16^{\mathrm{ab}} \pm 2,04$ & $42,5^{\mathrm{b}} \pm 2,73$ & $41,66^{\mathrm{b}} \pm 2,58$ & $38,33^{\mathrm{c}} \pm 2,58$ \\
Viabilitas(\%) & $66,9^{\mathrm{a}} \pm 1,41$ & $63,08^{\mathrm{b}} \pm 2,66$ & $59,31^{\mathrm{c}} \pm 1,43$ & $58,41^{\mathrm{cd}} \pm 2,88$ & $55,67^{\mathrm{d}} \pm 2,96$ \\
Abnormalitas(\%) & $4,8^{\mathrm{a}} \pm 0,92$ & $7,98^{\mathrm{b}} \pm 1,51$ & $8,61^{\mathrm{b}} \pm 1,45$ & $10,45^{\mathrm{c}} \pm 1,10$ & $10,53^{\mathrm{c}} \pm 2,96$ \\
\hline
\end{tabular}


Tabel 3. Sexing spermatozoa kromosom X dan Y pada kontrol dan kedua sisi anoda dan katoda

\begin{tabular}{cccccc}
\hline \multirow{2}{*}{ Parameter } & \multirow{2}{*}{ Kontrol } & \multicolumn{2}{c}{5 menit } & \multicolumn{2}{c}{ 10 menit } \\
\cline { 3 - 6 } & & Katoda & Anoda & Katoda & Anoda \\
\hline Spermatozoa Y $(\%)$ & $51^{\mathrm{a}} \pm 1,50$ & $44,17^{\mathrm{a}} \pm 2,04$ & $56,83^{\mathrm{a}} \pm 2,06$ & $37,83^{\mathrm{a}} \pm 0,40$ & $67,33^{\mathrm{a}} \pm 1,03$ \\
Spermatozoa X $(\%)$ & $49^{\mathrm{a}} \pm 1,50$ & $55,83^{\mathrm{b}} \pm 2,04$ & $43,17^{\mathrm{b}} \pm 2,06$ & $62,17^{\mathrm{b}} \pm 0,240$ & $32,67^{\mathrm{b}} \pm 1,03$ \\
Jumlah $(\%)$ & 100 & 100 & 100 & 100 & 100 \\
\hline
\end{tabular}

Motilitas semen segar yang dipakai dalam proses semen beku di BBIB Singosari yaitu di atas $60 \%$ dan minimal mempunyai kecepatan massa +2 . Penelitian ini menggunakan semen sapi Bali di BBIB Singosari minimal mempunyai motilitas $45 \%$. Motilitas semen segar Sapi Bali di penelitian ini sebesar $48,33 \pm 2,58 \%$ dengan kecepatan $+2-+3$. Hasil pemeriksaan konsentrasi semen pada sapi Bali yaitu 1001,33 $\pm 148,59$ x $10^{6} / \mathrm{ml}$. Konsentrasi semen sapi yang normal berkisar antara $800 \times 106-2000 \times 106 / \mathrm{ml}$ (Garner and Hafez, 2008).

Hasil pemeriksaan motilitas, viabilitas, dan abnormalitas semen hasil sexing pada motilitas dan viabilitas mengalami penurunan sedangkan pada abnormalitas mengalami peningkatan. Hasil pemeriksaan motilitas, viabilitas, dan abnormalitas semen hasil sexing pada durasi lima menit hasilnya lebih baik dibanding hasil sexing pada durasi waktu sepuluh menit (tabel 2). Motilitas spermatozoa pada penelitian ini mengalami penurunan kualitas hal ini sama dengan penelitian sebelumnya yang dilakukan oleh Prastiya dkk tahun (2014).

Hasil pemeriksaan motilitas, viabilitas, dan abnormalitas semen hasil sexing pada motilitas dan viabilitas mengalami penurunan sedangkan pada abnormalitas mengalami peningkatan. Hasil pemeriksaan motilitas, viabilitas, dan abnormalitas semen hasil sexing pada durasi lima menit hasilnya lebih baik dibanding hasil sexing pada durasi sepuluh menit. Hasil tersebut dikarenakan adanya tarikan spermatozoa dari sisi anoda dan katoda. Spermatozoa yang berkromosom Y akan tertarik ke sisi anoda sedangkan spermatozoa yang berkromosom $\mathrm{X}$ akan tertarik ke sisi katoda (Garner and Hafez, 2008).

Hasil perhitungan statistik (tabel 3) menunjukan tidak adanya perbedaan nyata pada kontrol $(\mathrm{p}<0,05)$ sedangkan pada perlakuan menunujukan perbedaan yang nyata $(p>0,05)$. Menurut hafs and boyd tahun 1986 yaitu pergerakan spermatozoa dengan menggunakan aliran listrik pada larutan ion lemah ditemukan 2 tipe spermatozoa yaitu tipe kepala anoda spermatozoa bergerak menuju anoda sedangkan tipe ekor katoda bergerak menuju sisi katoda. Spermatozoa yang tertarik ke sisi anoda diduga memiliki kromosom Y sedangkan spermatozoa yang tertarik ke sisi katoda diduga memiliki kromosom X (Shirai et al., 1989).

Penelitian sebelumnya dilakukan Hafs and Boyd pada tahun 1986 dengan menggunakan electrophoresis yang dialiri listrik sebesar 8 Volt dan 21 Volt selama satu menit pada sapi. Hasil penelitiannya menunjukan berhasil memisahkan $55 \%$ pada sisi anoda. Hasil tersebut menunjukan bahwa penilitian ini jauh lebih baik darapada penelitian sebelumnya yaitu pada sisi anoda dengan durasi sepuluh menit sebesar 67,33\% dengan dialiri listrik 1,5 Volt pada sisi anoda dan katoda..

Persentase efektivitas pada anoda yang di sexing selama sepuluh menit lebih tinggi yaitu sebesar $67,33 \pm 1,03 \%$ dibanding katoda yang di sexing selama sepuluh menit yaitu sebesar $62,17 \pm 0,24 \%$. Hasil tersebut menunjukan bahwa pada sisi anoda jauh lebih baik dibanding pada sisi katoda. Hasil ini menunjukan bahwa durasi waktu dalam proses sexing sangat mempengaruhi hasil kualitas sexing, dengan durasi waktu yang tepat akan dapat memberikan hasil kualitas sexing yang optimal (Sunarti dkk., 2016).

\section{KESIMPULAN}

Kualitas sexing spermatozoa terbaik menggunakan alat ESS adalah pada durasi lima menit, sedangkan efektivitas sexing spermatozoa terbaik pada durasi sepuluh menit. 


\section{UCAPAN TERIMA KASIH}

Peneliti mengucapkan terima kasih kepada Balai Besar Inseminasi Buatan di Singosari atas izin yang diberikan untuk melakukan penelitian.

\section{DAFTAR PUSTAKA}

Ducha, N., Susilawati, T., Aulanni'am, Wahjuningsih, S. 2013. Motilitas dan Viabilitas Spermatozoa Sapi Limousin Selama Penyimpanan pada Refrigerator dalam Pengencer Cep-2 dengan Suplementasi Kuning Telur. Jurnal Kedokteran Hewan, 7(1), 5-8.

Garner, D.L., Hafez, E.S.E. 2008. Spermatozoa and Seminal Plasma. In Reproduction in Farm Animal. Edited By Hafez, E. S. E., and B. Hafez 7th Edition. Blackwell Publishing. USA: p96-108.

Guntoro, S. 2002. Membudidayakan Sapi Bali. Penerbit Kanisius. Yogyakarta.

Hafs, H.D., Boyd, L.D. 1986. Galvanic separation of $\mathrm{X}$ and $\mathrm{Y}$ Chromosome Bearing Spermatozoa. In SE Hafez (ed). Reproduction in Farm Animals 5th edition, By Lea and Febiger. Philadelphia. p498-500.

Pamungkas, F.A., Mahmilia, F., Elieser, S. 2008. Perbandingan Karakteristik Semen Kambing Boer dengan Kacang. Seminar Nasional Teknologi Peternakan dan Veteriner 2008.

Prastiya, R.A., Saputro, A.L., Zainab, S., Hermadi, H.A. 2014. Perbandingan Kualitas Spermatozoa Hasil Pemisahan Kromosom X dan Y Antara Metode Kolom Albumin dan Metode Electric Separating Sperm (ESS) pada Domba Ekor Gemuk. Veterinaria Medika. Surabaya.

Ridwan. 2009. Pengaruh Pengencer Semen terhadap Abnormalitas dan Daya Tahan Hidup Spermatozoa Kambing Lokal pada
Penyimpanan Suhu $5^{\circ}$ C. J. Agroland, 16(2), 187-192.

Rizal, M., Herdis. 2010. Inseminasi Buatan pada domba. Penerbit Rineika Cipta. Jakarta.

Rodiah, E. Yuliani, A.S., Dradjat, C., Arman. 2015. Efektifitas Kinerja Pentoksifilin Terhadap Kualitas dan Integritas Membran Plasma Utuh pada Sperma Sapi Bali Hasil Pemisahan dengan Menggunakn Albumin. Jurnal Ilmu dan Teknologi Pertenakan Indonesia, 1(1), 60-65.

Said, S., Kaiin, E.M., Tappa, B. 2005. Produksi anak sapi potong dan sapi perah berjenis kelamin sesuai harapan. Prosiding Seminar Nasional Industri Peternakan Modern II. Puslit Bioteknologi LIPI, Mataram.

Saputro, A.L. 2012. Kualitas Spermatozoa Domba Merino Pada Sisi Anoda Hasil Pemisahan Dengan Teknis Anoda. Universitas Airlangga. Surabaya.

Shirai, M., Matsuda, M.S., Mitsuhawa. 1989. Electrophoresisi separation of $\mathrm{X}$ and $\mathrm{Y}$ chromosome bearing sperm in human sperm. Dalam N. Isnaini. 1994. Pemisahan spermatozoa X dan Y pada sapi FH dengan sentrifugasi. p121-129.

Sunarti, Saili, T., Nafiu, L.O. 2016. Karakteristik Spermatozoa Sapi Bali Setelah Sexing Menggunakan Metode Kolom Albumin Dengan Lama Waktu Sexing Yang Berbeda. Pertenakan UHO. JITRO, 1(1).

Tambing, S.N., Toelihere, M.R., Yusuf, T.L., Bambang, P., Sutama, I.K., Polmer, Z.S. 2003. Pengaruh Frekuensi Ejakulasi Terhadap Karakteristik Semen Segar dan Kemampuan Libido Kambing Saanen. J. Sain Vet., 21(2), 57-65.

Taylor, T.M. 2005. Comparing Calf Sex Ratio and Semen Sex Ratio Determined by Conventional PCR. [Thesis]. The 
Interdepartmental Program In Animal and Dairy Sciences. Southern Arkansas University, Arkansas.
Varasofiari, L.N., Setiatin, E.T., Sutopo. 2013. Evaluasi Kualitas Semen Segar Sapi Jawa Brebes Berdasarkan Lama Waktu Penyimpanan. Animal Agriculture Journal, 2 (1), 201-208. 